\title{
Cuento
}

\section{Alea iacta est}

\section{Carlos Saussure Figueroa-Portilla ${ }^{1}$}

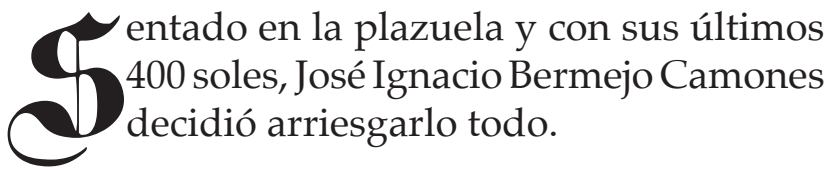

Su sueño no le podía fallar, hoy ganaba Japón, ganaba sí o sí.

En la mañana, su esposa le había contado que un gorrión se había posado en la ventana de la cocina que daba al jardincito.

— ¿Un gorrión?

-Sí

— ¿En Lima?

-Sí

- ¿En invierno?

-Sí, carajo, ya te dije que sí.

Avergonzado, José Ignacio empezó a creer.

Al fin los meses de mala racha se estaban yendo. ¿Era una señal?, quizás la primera de un conjunto de señales que solo llevan a un inevitable y feliz puerto: la buena suerte.

Horas más tarde, Leiner, su hijo menor, le había dicho feliz que por primera vez, desde que se mudaron, los perros no habían orinado en la puerta.

- ¿No orinaron nada?

-No, papá

— ¿Ni gotitas ni nada?

Docente universitario (UNMSM) y podcáster. Magíster en Innovación e Integración educativa de las TIC (PUCP). Licenciado en Educación Secundaria con mención en Especialidad Informática. Lima, Perú.
-Ay, qué cochino, papá. Nada de nada, ni chorros ni gotas de nada, nada de nada, está todo seco.

Ya van dos, se dijo. Pero dos no es nada, se decía a sí mismo, incrédulo por las décadas de mala suerte; pues 30 años atrás, cuando niño, juntó todos sus ahorros, y para asegurarse de ganar en una pequeña rifa de su colegio, compró más del cincuenta por ciento de todos los boletos puestos en venta. Resultado: los boletos ganadores pertenecían al otro 50\% que no compró.

Un grito de felicidad lo trajo de vuelta a la realidad. Sara, su hija, que acababa de ingresar a la universidad, salía feliz del baño con un test de embarazo en la mano.

— ¡Es negativo!, le dijo a su padre, mientras le mostraba la única línea en el test.

Era la señal que esperaba José Ignacio. Tres de tres. ¡Como nunca!

Llegó corriendo a la casa de apuestas. Estaba llena. Una cola que rememoró en él los más terribles años de la hiperinflación.

Un tipo enorme en la puerta, vestido en short y bivirí percudido, gritaba:

— ¡Ya no hay apuestas para Japón!

— ¡La puta madre, lo sabía!, pensó José Ignacio — ¡Lávese esa boca, hay niños en la fila!, le gritó una señora.

Aturdido aún por la noticia, poco le importaron las cuarenta personas que esperaban antes 
que él. Así que sin mucho que pensar, respiró profundo y avanzó a empujones entre el tumulto.

_Oye, imbécil, no empujes!, le gritaba la gente.

Con dos botones rotos de la camisa, logró entrar a la casa de apuestas.

-100 a Japón, dijo.

-Japón da 6 a 1 si gana, gritaba el dueño del local.

—Dale 100 nomás.

- Tome su ticket.

El partido comenzó. Una escuadra japonesa bien ordenada. Con juego limpio, de lo más correcto que se puede ver. Ningún foul ni caídas innecesarias. Bélgica se defendía como podía. Primer gol. Va ganando Japón. José Ignacio gritaba de emoción.

En la radio, el narrador:

-Yamaguchi, Honda, ¡Kagawa! Saque de meta. Pitazo. Ha culminado el primer tiempo de este encuentro Japón-Bélgica. $Y$ vemos a una escuadra japonesa haciendo lo que quiere en la cancha con el equipo Belga.

José Ignacio estaba ansioso. ¿Y si le pongo 100 más?, pensaba. No. La suerte es traicionera. Mejor lo dejo en 100.

Comenzó el segundo tiempo. Japón seguía dominando el partido. Los minutos pasaban. Seguía 1-0. De pronto, un puntazo directo al arco puso el 2 a 0 para Japón. Ya iban 30 de los 45 minutos del segundo tiempo.

-2-0 es imposible voltear, pensó José Ignacio. No lo pensó más. Es mi oportunidad, se dijo. Y convenciéndose a sí mismo, gritó:

—Ponle 300 más a Japón.

- Ahora está dando 4 a 1. ¿Igual le vas?

-Igual, ponle 300 más.

Y como si los hilos del destino fuesen manejados por seres cuyo afán es mofarse de la desgracia ajena y regodearse en la miseria humana, ni bien recibió el ticket de apuesta se escuchó en la radio:

- ¡Gol de Bélgica!

-Al menos 2 a 1, el partido está liquidado de todas formas, se convencía José Ignacio.

Minuto 45 del segundo tiempo. José Ignacio había salido de la casa de apuestas. Esperaba afuera, no soportaba el bochorno ni la bulla de la gente. Y nuevamente gol de Bélgica. Empate.

— ¡La puta madre, tiempo suplementario!, gritaba José Ignacio.

— ¡6 minutos de tiempo adicional!, murmuraba la gente en la calle.

No importa, pensaba José Ignacio. En el tiempo suplementario ganamos.

Minuto 50 del segundo tiempo, 5 minutos del tiempo adicional. Gol de Bélgica.

Un intenso escozor invadió el cuerpo de José Ignacio. Un nudo en la garganta le impidió gritar de rabia. Por su rostro caían lágrimas de ira y desesperación. Lo había perdido todo. Ya no tenía nada. ¿Qué diría al llegar a su casa? ¿Qué iban a comer mañana?

Con la mirada perdida, arrastrando los pies por la vereda, doblo la esquina de su casa, tocó la puerta. Nadie respondía. Buscó en su casaca la llave, abrió la puerta. Se tiró al sofá, desconsolado. Al bajar la mirada vio la prueba de embarazo de su hija. Ahora la prueba tenía dos rayitas.

\section{Correspondencia:}

Carlos Saussure Figueroa Portilla

csfigueroa@pucp.pe

FECHA DE RECEPCIÓN: 14-06-2020.

FECHA DE ACEPTACIÓN: 07-07-2020. 